OPEN ACCESS

Edited by:

Peng $\mathrm{Hu}$,

Chongaing Medical University, China

Reviewed by:

Demin Cai,

Yangzhou University, China

Wenzhi Guo,

The First Affiliated Hospital of

Zhengzhou University, China

*Correspondence:

Bo Xiang

xb_scu_edu@163.com

Specialty section:

This article was submitted to Human and Medical Genomics,

a section of the journal

Frontiers in Genetics

Received: 17 August 2021 Accepted: 11 November 2021

Published: 25 November 2021

Citation:

Kong M and Xiang B (2021) Identifying Biomarkers to Predict the Prognosis of Biliary Atresia by Weighted Gene Co-

Expression Network Analysis.

Front. Genet. 12:760182.

doi: 10.3389/fgene.2021.760182

\section{Identifying Biomarkers to Predict the Prognosis of Biliary Atresia by Weighted Gene Co-Expression Network Analysis}

\author{
Meng Kong and Bo Xiang * \\ Department of Pediatric Surgery, West China Hospital, Sichuan University, Chengdu, China
}

The prognosis of children with biliary atresia (BA) after Kasai operation remains difficult to predict, and liver fibrosis is closely related to the prognosis of children with BA. We aimed to find biomarkers for native liver survival (NLS) prediction by weighted gene co-expression network analysis (WGCNA). The biological processes and signal pathways that biomarkers involved in were further analyzed by bioinformatics. Quantitative Real-time PCR, Western blot and immunohistochemistry was performed to detect biomarkers expression. The relationship of biomarkers with clinicopathological characteristics of BA was also investigated. LECT2 was overexpressed or knockdown in LX-2 cells, and the expression of fibrogenic genes such as a-SMA and COL1A1 was quantified. We found that LECT2 mRNA expression was higher in BA liver tissues compared with normal liver tissues. Bioinformatics showed that LECT2 mainly played a fibrosis-promoting role in the development in BA by regulating bile acid metabolism and promoting inflammatory response. LECT2 immunohistochemistry scores of BA children were higher than control group $(p=0.001)$. Survival analysis revealed that LECT2 high expression is an unfavorable prognostic factor for native liver survival in BA patients. Additionally, the high LECT2 expression was an independent prognostic factor affecting native liver survival (HR 3.702, 95\%Cl:2.085-6.575, $p=0.001$ ). LECT2 modulates TGF- $\beta$ mediated $a-S M A$ and COL1A1 expression in LX-2 cells. siRNA-LECT2 inhibits the expression of a-SMA and COL1A1 in LX-2 cells. Overexpression of LECT2 resulted in an increase in a-SMA and COL1A1 expression. Knockdown of LECT2 inhibits the proliferation and increase apoptosis in activated LX-2 cells. LECT2 may act as a new prognostic biomarker for native liver survival in BA patients.

Keywords: LECT2, prognosis, native liver survival, biliary atresia, WGCNA

\section{INTRODUCTION}

Biliary atresia (BA) is a severe, progressive obstructive biliary disease that occurs in infancy and is a common cause of neonatal jaundice (Hartley et al., 2009). Inflammatory bile duct obstruction and liver fibrosis are the key factors affecting the survival of children with BA. Since the Kasai procedure was performed in 1959, the prognosis of BA children has gradually improved (Chardot et al., 1999). However, despite the Kasai procedure, more than $60 \%$ of children still need liver transplantation to save their lives due to recurrent cholangitis and cholestatic cirrhosis after surgery (He et al., 2021). 
Furthermore, Kasai surgery does not stop the progression of liver fibrosis, and about $70-80 \%$ of children with liver fibrosis continue to progress, affecting long-term prognosis (Bijl et al., 2013). How to prolong the survival time of native liver in BA children and delay liver transplantation is an urgent clinical problem.

In recent years, the development of bioinformatics has greatly contributed to the understanding of diseases and helped to analyze the role of individual genes in the disease process at the genomic level as a whole. The weighted gene co-expression network analysis (WGCNA) can screen gene modules closely related to diseases by analyzing the correlation between genomic and clinical information, thus providing a basis for further experimental studies (Luo et al., 2015). In this study, we analyzed the gene expression profile of patients with BA by WGCNA algorithm and screened that the key genes associated with hepatic fibrosis in biliary atresia is LECT2 (Leukocyte Cell Derived Chemotaxin 2). LECT2 is a protein coding gene and has a neutrophil chemotactic activity. LECT2 is involved in many immune processes, such as regulation of sepsis, regulation of hepatocellular carcinoma cells, and regulation of neurological diseases (Zheng et al., 2013).

Continued progressive liver fibrosis is one of the most important factors affecting the prognosis of $\mathrm{BA}$, and we need to prevent or slow down the occurrence of liver fibrosis in our clinical work. In reviewing the literature, no data was found on the association between LECT2 and native liver survival of biliary atresia patients. In this study, we analyzed the relationship of LECT2 with native liver prognosis in BA patients, and identified the potential prognosis value for BA patients.

\section{METHODS}

\subsection{Microarray Data of Biliary Atresia and Bioinformatics Analysis}

The gene expression profiles of biliary atresia were obtained from the Gene Expression Omnibus (available at http://www.ncbi.nlm. nih.gov/geo) database. GSE46960 and GSE15235 dataset were included in our study. The GSE15235 included 26 fibrosis biliary atresia liver tissues and 17 inflammatory biliary atresia liver tissues. The GSE46960 included 64 biliary atresia liver tissues, 14 diseased control liver tissues and seven normal liver tissues. GSE15235 was used for WGCNA analysis, and the annotation information of the chip was obtained from the GPL570 platform. The "Affy" package in R language (version 4.1) was used for preprocessing of raw data (Sásik et al., 2002), and the "WGCNA" package in $\mathrm{R}$ language was used for the construction of weighted gene co-expression networks and module identification, and the modules that were significantly correlated with clinical phenotypes were extracted (Langfelder and Horvath 2008). Firstly, the gene expression matrix correlation coefficients were weighted to make the interaction relationships between genes conform to the scale-free distribution. Then the genes were classified and genes with similar expression patterns were divided into a module. Then the characteristics of the modules were studied to identify the modules most associated with BA liver fibrosis. Finally, the network regulatory relationships between genes within the modules were explored, and hub genes were extracted using Cytoscape and visualized for protein-protein interactions (PPI) analysis (Killcoyne et al., 2009). Gene Set Enrichment Analysis (GSEA) was used to analyze the potential role of LECT2 in the development of BA. The mRNA expression data of BA patients were obtained from the above GEO data, and GSEA was used to annotate the role of LECT2 in BA. GSEA v4.1.0 for Windows (http://www.gseamsigdb.org/gsea/index.jsp) was downloaded, and gene sets were obtained from Molecular Signatures Database v7.4 for analysis and visualization of results with $p<0.05$ and false discovery rate $(\mathrm{FDR})<0.05$ were statistically significant (Subramanian et al., 2005).

\subsection{Patient Selection and Tissue Sampling}

Total 205 children with biliary atresia after Kasai operation admitted to our hospital between January 2015 and December 2020 were selected as the case group. Inclusion criteria: The age of surgery was less than 180 days and the liver tissue of the child was pathologically diagnosed as biliary atresia. Exclusion criteria: Those who no clear pathological diagnosis. Data was collected including gender, age at surgery, laboratory examination and Pediatric End-stage Liver Disease (PELD) score (Chang et al., 2018). During surgery, a $5 \mathrm{~mm}$-sized piece of liver tissue was excised from the lower edge of the right lobe of the liver. The liver tissue was placed in formalin solution and will be used for immunohistochemical staining. Forty children with hepatoblastoma were selected, and normal liver tissue adjacent to the tumor were taken as the control group. The collection of samples for this study was approved by the Biomedical Research Ethics Committee (No.1082) and informed consent was obtained from the parents of the patients. All the BA children were followed up after surgery, with a median follow-up time of 18 months (3-60 months). A native liver survival (NLS) status within 5 years post-Kasai operation was also recorded in the study.

\subsection{Immunohistochemical Analysis}

Liver tissues were sectioned, dewaxed, rinsed, incubated with $0.3 \% \mathrm{H}_{2} \mathrm{O}_{2}$ for $5 \mathrm{~min}$ at room temperature. Slides were incubated with $5 \% \mathrm{BSA}$ in PBS for $30 \mathrm{~min}$ at $37{ }^{\circ} \mathrm{C}$ to block non-specific binding sites, then incubated with appropriate primary antibodies (anti-human LECT2 antibody, 1:150, ab119429) overnight at $4{ }^{\circ} \mathrm{C}$, followed by horseradish peroxidase anti-mouse IgG antibody for $1 \mathrm{~h}$. The slides were then incubated with DAB substrate kit for color development. Each pathological section was observed in five randomly selected fields under a highpowered microscope. Positive expression of LECT2 was defined as the presence of brown or yellowish-brown granular material in the cytoplasm. The score of LECT2 expression was determined by the proportion of positive cells and the degree of staining. According to the proportion of positive cells: 0 points $\leq 5 \%$; 1 point $6-25 \%$; 2 points $25-50 \%$; 3 points $50-75 \%$; four points $\geq 75 \%$. According to the degree of staining: 0 points: no staining; one point: light staining, slightly higher than the background color; two points: moderate staining; three points: strong staining. The total score was obtained by adding the 
proportion of positive cells and the staining degree score (-) 0-1 point $(+)$ two to three point $(++)$ four to five point $(++++)$ six to seven point, where $0-3$ was low expression and four to seven was high expression.

\subsection{Cell Culture}

The LX-2 cell line was inoculated with DMEM medium supplemented with $10 \%$ fetal bovine serum, $100 \mathrm{U} / \mathrm{ml}$ penicillin, and $100 \mathrm{mg} / \mathrm{ml}$ streptomycin, and cultured in an incubator at $37^{\circ} \mathrm{C}, 70 \%-80 \%$ humidity, and $5 \% \mathrm{CO}_{2}$. When the cell growth density reached $80-90 \%$, the cells were digested with $2 \mathrm{ml}$ trypsin and passaged. TGF- $\beta$ is the cytokine with the strongest effect in stimulating hepatic stellate cells (HSC) activation and secretion of extracellular matrix (ECM), so TGF- $\beta$ was used in this study to stimulate LX-2 cells in order to establish a liver fibrosis model.

\subsection{RNA Isolation and Quantitative Real-Time Polymerase Chain Reaction (qRT-PCR)}

Total 20 biliary atresia liver tissues and 10 normal liver tissues were used to RNA Isolation. Total RNA was extracted from liver tissue using Trizol, and total RNA was used for cDNA synthesis through NovoScript ${ }^{\circledR}$ first Strand cDNA Synthesis SuperMix (Novoprotein Scientific Inc. China). PCR amplification was performed using $\mathrm{SYBR}^{\circledR}$ Premix $\mathrm{Ex} \mathrm{Taq}^{\mathrm{TM}}$ kit and data analysis was performed by the $2^{-\Delta \Delta C t}$ method. LECT2 forward primer: GCTGGTCTGATTTCTACCGCA; LECT2 reverse primer: TCCAGCAGAGCACAAGATGTC.

\subsection{Plasmid Construction and RNA Interference}

The design and synthesis of LECT2-specific siRNA and pCS2LECT2 plasmid was done with the assistance of Tsingke Biotechnology Co., Ltd. LX-2 cells were cultured for $24 \mathrm{~h}$ and transfected according to the instructions of LipofectamineTM2000 (Invitrogen). The medium was changed after $6 \mathrm{~h}$ transfection and TGF- $\beta$ was added at a concentration of $10 \mathrm{ng} / \mathrm{ml}$ and continued to be cultured for $48 \mathrm{~h}$. The sequences of oligonucleotides used are as follows:

LECT2-siRNA (human):5' - UUUUGAGUGGGUAUCAAC CAG-3'; Negative scrambled siRNA:5'- GUUGAUACCCAC UCAAAAAGG-3';

LECT2-clone-F: 5' - TTGCAGGATCTGCCACCATGTTTT CCAC-3';

LECT2-clone-R: 5' - ATTGATGCCTCGAGCCCGGGTTAC AGGTATG-3'.

\subsection{Western Blot}

Whole cell proteins were lysed with RIPA buffer containing $1 \%$ PMSF, centrifuged at $15,000 \mathrm{r} / \mathrm{min}$ for $30 \mathrm{~min}$, and the supernatant was collected. The protein was extracted using the protein extraction kit according to the instructions, and the protein concentration was determined by the BCA kit. $20 \mu \mathrm{g}$ of protein was separated by $10 \%$ SDS-PAGE, and transferred to
PVDF membrane. The membrane was closed with 5\% skim milk for $1 \mathrm{~h}$ at room temperature, and diluted LECT2 primary antibody, a-SMA primary antibody, Col $1 \alpha 1$ primary antibody, and $\beta$-actin primary antibody were added and incubated overnight at $4^{\circ} \mathrm{C}$. TBST washed 3 times, and diluted HRPlabeled secondary antibody was added and incubated for $2 \mathrm{~h}$ at room temperature. ImageJ software was used to analyze and calculate the grayscale values.

\subsection{Cell Proliferation}

The cell density of LX- 2 cells was adjusted to $4 \times 10^{5}$ cells/well, and when the cell density reached $80 \%, 10 \mathrm{ng} / \mathrm{ml}$ TGF- $\beta$ was added and the culture was continued for $24 \mathrm{~h}$. Subsequently, transfection was performed. After 24, 48, 72 and $96 \mathrm{~h}$ of incubation, $20 \mu \mathrm{L}$ of CCK- 8 reagent was added to each well. Set the enzyme marker at $450 \mathrm{~nm}$ and detect the OD value of the cell CCK-8 mixture for viability analysis.

\subsection{Cell Apoptosis}

According to the manufacturer instruction of Annexin-V-FITC Apoptosis Detection Kit, the LX-2 cell concentration was adjusted to $5 \times 10^{5}$ cells $/ \mathrm{ml}$, and the cells were resuspended with $400 \mu \mathrm{L}$ of Binding Buffer. Add $5 \mu \mathrm{L}$ AnnexinV-FITC staining solution to the above cell suspension, mix well, and incubate for $15 \mathrm{~min}$. Add $10 \mu \mathrm{L}$ PI staining solution and incubate for $8 \mathrm{~min}$. Transfer the cell suspension into a flow cytometry plastic tube and perform cell apoptosis analyses on the BD FACSVerse machine.

\subsection{Statistical Analysis}

All data were analyzed by $\mathrm{R}$ software (R 4.1.0). The Chi-Square test was used to compare the rates, and the non-parametric test was used to compare the quantitative variables. Survival curves were calculated using the Kaplan-Meier method, and differences were tested with log-rank tests. The Cox proportional risk model was used to determine independent factors based on the variables selected by univariate analysis. The $p<0.05$ was considered statistically significant.

\section{RESULT}

\subsection{Bioinformatics Analysis and Hub Genes}

In this study, when the soft threshold is 7 , the $R^{2}$ of Scale Free Topology Model reached 0.8 , and the $R^{2}$ tends to be stable (Figure 1A). A total of 24 gene modules and one grey module were obtained, and different modules were assigned different colors, among which the grey module corresponded to those genes that were not included in any module, and the modules with more genes clustered were blue, turquoise and darkred modules (Figure 1B). The correlation between the salmon module and the clinical phenotype was high $(\mathrm{r}=0.79, p<$ 0.001 ), suggesting that the genes in the salmon module were significantly correlated with the clinical phenotype of liver fibrosis (Figure 1C). The hierarchical clustering heat map shows that the correlation between the genes within the modules is high, and it also shows that the modules are not independent of each other, but are also correlated (Figure 1D). The genes in the salmon 

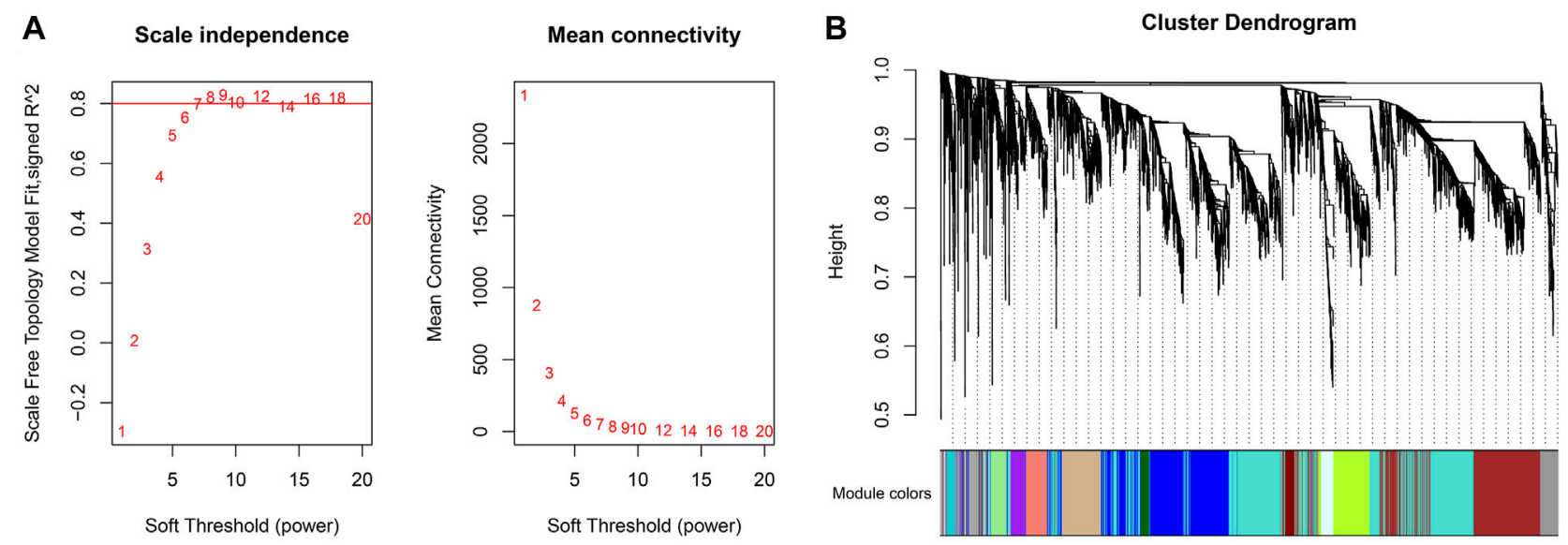

C

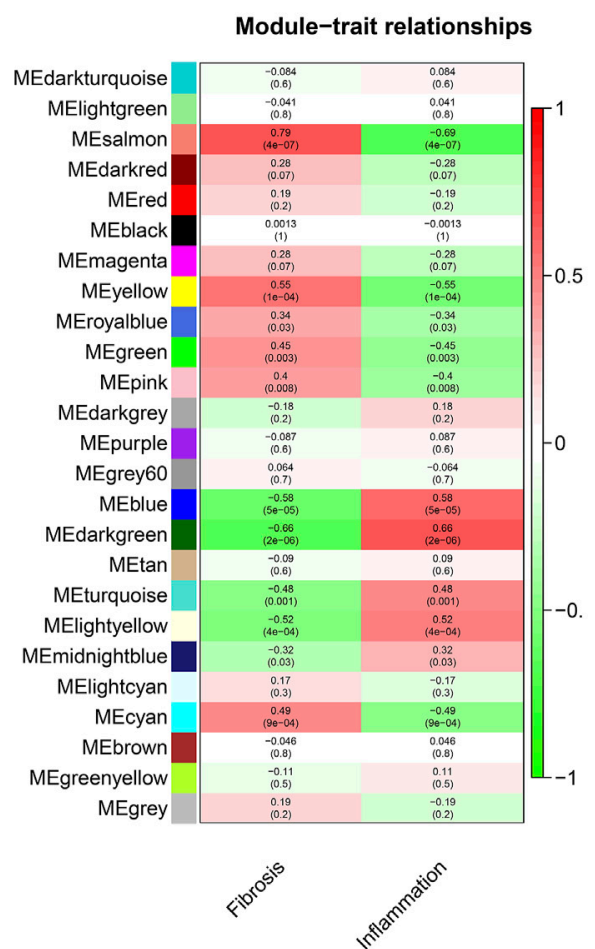

D
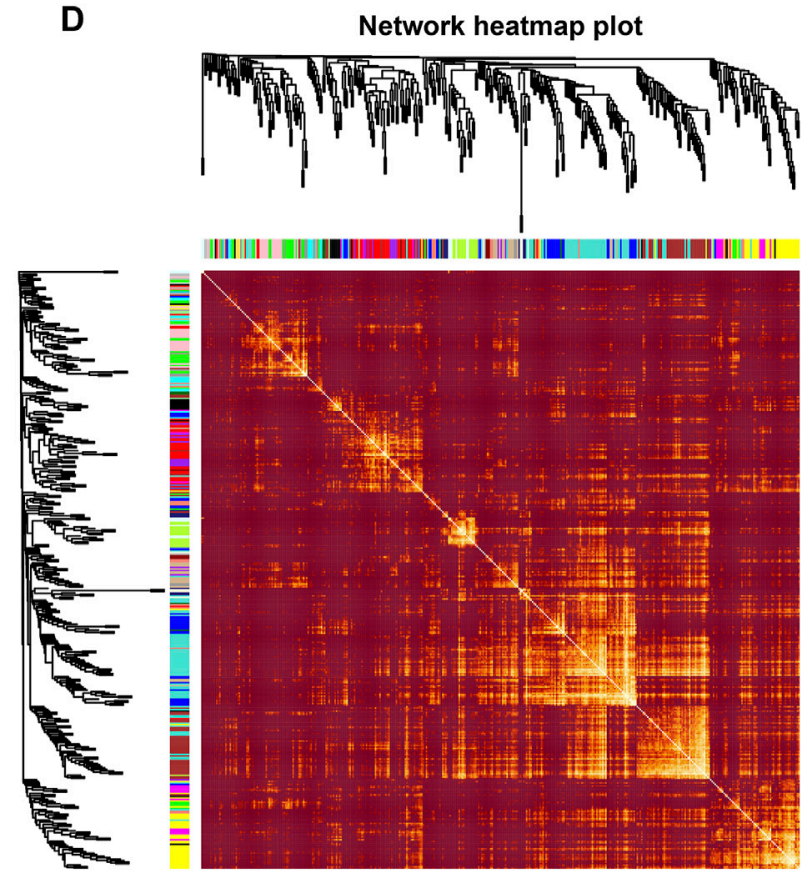

FIGURE 1 | Construction of co-expression modules (A) Determination of soft-threshold power (B) The cluster dendrogram of genes (C) Heatmap of the moduletrait relationships (D) Network heatmap plots of genes selected for WGCNA construction.

module were analyzed using Cytoscape, and hub genes were extracted through the plugin MCODE. LECT2 is located at the core of the network (Figure 2A). The results of GSEA analysis showed that LECT2 is involved in BA development mainly through regulation of bile acid metabolism, activation of genes involved in the inflammatory response, activation of TNF- $\alpha$ signaling pathway and IL16 signaling pathway (Figure B).

\subsection{LECT2 Expression in Liver Tissue}

GSE46960 was used to validated the mRNA expression level of LECT2 in biliary atresia. The mRNA expression of LECT2 was found increased in biliary atresia liver tissues (Figure Figure3A).
Then, we examined the expression of LECT2 in biliary atresia liver tissues and normal liver by qRT-PCR. The result showed that the expression of LECT2 in BA liver tissues was higher than that in normal liver tissues (Figure 3B). Additionally, immunohistochemistry was used to detect the LECT2 protein expression in BA. Total 205 BA children underwent Kasai surgery in our hospital, including 89 males and 116 females, and all children were followed up from 1 month to 60 months. There were 104 BA patients survived 5 years with native liver after Kasai surgery, with a 5 years native liver survival rate of $54.6 \%$ and a median survival time of 32.8 months. Total 101 children underwent liver transplantation or died due to liver function 

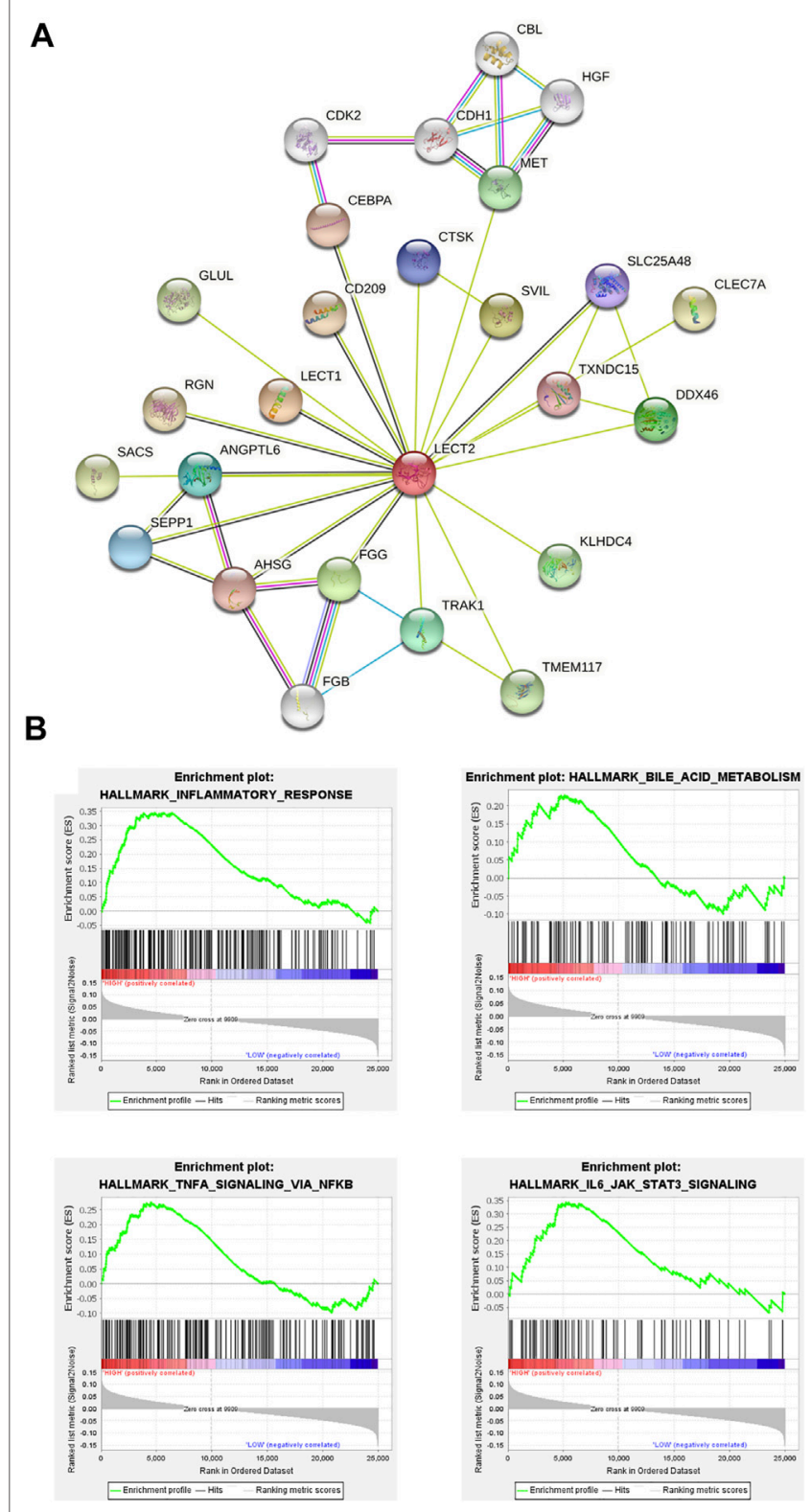

FIGURE 2 | Identification of hub genes (A) The protein-protein interaction (PPI) network (B) Gene set enrichment analysis.

failure. The clinical information of BA was summarized in Table 1. LECT2 was mainly expressed in the cytoplasm of hepatocytes. LECT2 was highly expressed in the cytoplasm of biliary atresia hepatocytes (Figure 3C). LECT2 protein expression in biliary atresia $(87.8 \%)$ was significantly higher than in control group (7.5\%, $p<0.01$; Table2).

\subsection{Correlation of LECT2 Expression in Biliary Atresia and Native Liver Survival}

The children were divided into high LECT2 expression group and low LECT2 expression group. The native liver survival rate of BA children in the low LECT2 expression group was $78.1 \%$. The native liver survival rate of BA children in the high LECT2 expression group was $26.6 \%$. In the low LECT2 expression group, the median survival time after Kasai surgery was 58 months. The median survival time after Kasai surgery was 16 months in the high LECT2 expression group. The Log-Rank test showed a statistically significant difference in the native liver survival rate between the two groups $(p<0.001)$, and the survival rate comparison curves are shown in Figure 4. Based on the results of the univariate analysis, a multivariate COX regression analysis was performed for the seven statistically significant influencing factors: Growth failure, PELD score, TB, DB, IB, INR and LECT2 expression. The high LECT2 expression was an independent prognostic factor affecting native liver survival (Table3). BA patients with high LECT2 expression had a 3.7-times higher native liver mortality risk than patients with low LECT2 expression.

\subsection{LECT2 is Involved in Regulating the Formation of Hepatic Fibrosis in Biliary Atresia}

Progressive liver fibrosis is one of the most important factors affecting the prognosis of biliary atresia children, and hepatic stellate cells are the key cells involved in the development of biliary atresia liver fibrosis. TGF- $\beta$ is considered to be an important pro-fibrotic cytokine. We induced LX-2 cell activation with different concentrations of TGF- $\beta(2,5$, and $10 \mathrm{ng} / \mathrm{ml}$ ). Real-time qPCR results showed that the mRNA expression of LECT2, a-SMA, and COL1A1 was significantly increased in the experimental group (Figure 5A). Western blot showed that the protein expression of LECT2, $a$-SMA, and COL1A1 was significantly increased in the experimental group (Figure 5B). We used siRNA transient transfection technique to silence LECT2 in LX-2 cells and observed its effect on fibrosis indexes. Real-time qPCR results showed that the mRNA expression of LECT2, $a$-SMA, and COL1A1 were significantly higher in the experimental group after $24 \mathrm{~h}$ of TGF- $\beta(10 \mathrm{ng} / \mathrm{ml})$ stimulation compared with the normal group. In contrast, the expression of LECT2, a-SMA, and COL1A1 was significantly decreased after transfection with siRNA-LECT2 (Figure 5C). The Western Blot results also showed that transfection with siRNALECT2 significantly decreased the protein expression levels of LECT2, $a$-SMA, and COL1A1 under the same conditions (Figure 5D). These results suggest that silencing of the LECT2 gene decreased the index of fibrosis in LX-2 cells. To further confirm the pro-fibrotic effect of LECT2, the plasmid pCS2-LECT2 was transfected in LX-2 cells to overexpress LECT2. The result showed that LECT2, $a$-SMA, and COL1A1 protein and mRNA expression were significantly increased after transfection with pCS2-LECT2 compared to the control group (Figures 5E-F). This also indicated that LECT2 could promote the elevation of fibrosis indicators.

\subsection{The Effect of LECT2 on LX2 Cells Proliferation and Apoptosis}

CCK8 results showed that the proliferation of LX-2 cells in the transfected siRNA-IRF3 group was significantly inhibited 

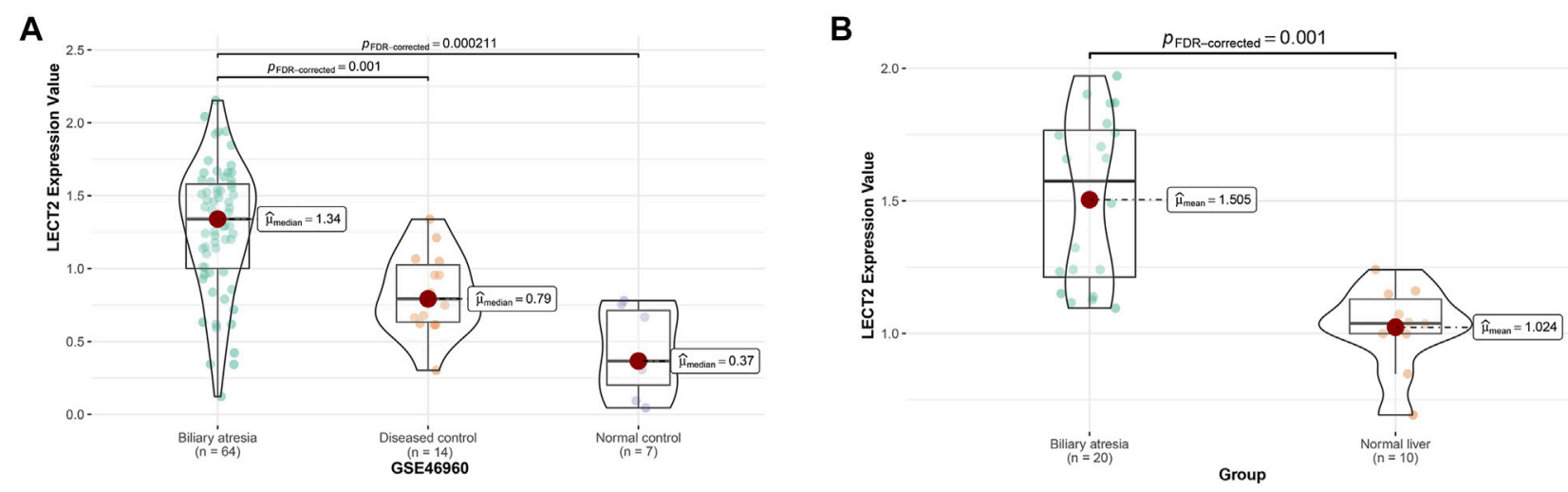

C
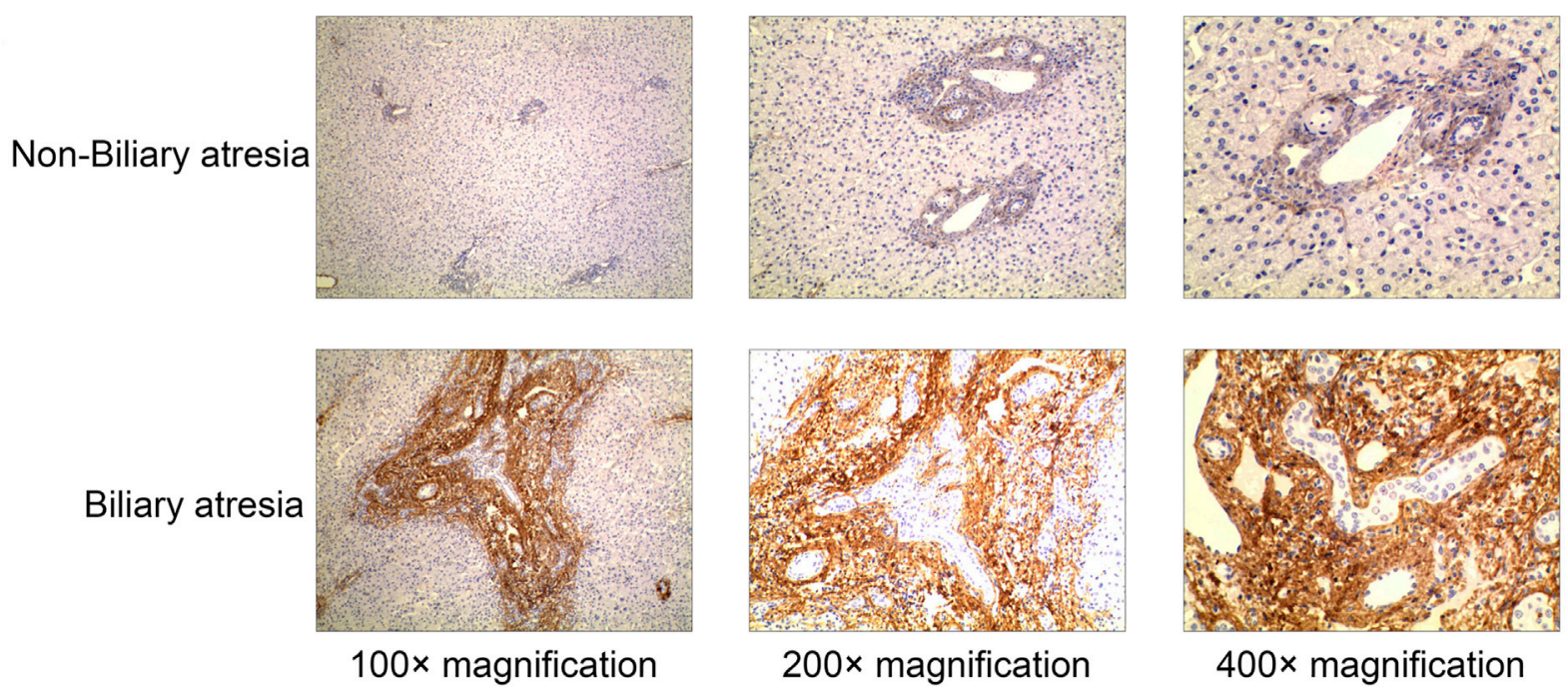

FIGURE 3 | The expression of LECT2 in biliary atresia (A) The relative expression of LECT2 in GSE46960 (B) The relative expression of LECT2 in clinical specimens (C) Immunohistochemistry for LECT2 in biliary atresia and non-biliary atresia groups.

compared with the control group (Figure 6A). Flow cytometry results showed that the proportion of apoptotic cells was significantly increased in LX-2 transfected with siRNA-LECT2 compared with the control group (Figure 6B).

\section{DISCUSSION}

Biliary atresia is a common cause of pathological jaundice in infants, with complex etiology, and the major pathological changes of BA were collagen deposition and liver tissue fibrosis, which can eventually lead to death of the child (Cielecka-Kuszyk et al., 2021). Studies have shown that liver fibrosis plays an important role in the course of BA and that the process of liver fibrosis does not stop after Kasai surgery in children with BA (Zhou et al., 2016). In this study, using the WGCNA algorithm, we found that the salmon module was most associated with biliary atresia liver fibrosis. The hub gene screened by PPI network was LECT2, which may be a key gene in the development of biliary atresia liver fibrosis.
In our study, the expression of LECT2 in BA liver tissues was higher than that in normal liver tissues. LECT2, a chemotactic factor produced by tissue cells in response to external stimulation, plays an important role in cellular signaling pathways and is a key site in the complex regulation network of liver fibrosis (Xu et al., 2019), but no study has reported the prognosis value of LECT2 in biliary atresia. In vitro experiments, LECT2 has specific chemotactic effects on neutrophils, monocytes and macrophages (Okumura et al., 2009). In the pathogenesis of hepatitis, LECT2 is preferentially expressed in hepatocytes in its most basic molecular structure and enters the blood to participate in the inflammatory response. The LECT2-deficient mice treated with concanavalin A resulted in increased liver injury, probably because immune cells such as $\mathrm{CD}^{+} \mathrm{T}$ lymphocytes and macrophages were affected by LECT2 deficiency (Saito et al., 2004). Plasma LECT2 levels were positively correlated with visceral fat area and its differential expression was associated with metabolic and dyslipidemia (Tanisawa et al., 2017). When serum glutathione aminotransferase levels reached a peak, the serum LECT2 levels were lowest in patients with acute liver failure, and serum LECT2 
TABLE 1 | Clinical information of biliary atresia patients.

\begin{tabular}{|c|c|c|c|c|}
\hline & $\begin{array}{c}\text { Overall } \\
(\mathrm{N}=205)\end{array}$ & $\frac{\text { Native liver survival }}{(N=104)}$ & $\frac{\text { Native liver death }}{(N=101)}$ & $p$ Value \\
\hline \multicolumn{5}{|l|}{ Gender } \\
\hline Female & 116 (56.6\%) & 60 (57.7\%) & 56 (55.4\%) & \\
\hline Male & 89 (43.4\%) & 44 (42.3\%) & 45 (44.6\%) & 0.854 \\
\hline \multicolumn{5}{|l|}{ Age(day) } \\
\hline Mean (SD) & 75.7 (22.2) & 74.5 (22.4) & $77.0(22.1)$ & 0.408 \\
\hline \multicolumn{5}{|l|}{ Weight(kg) } \\
\hline Mean (SD) & $5.17(1.08)$ & $5.21(1.04)$ & $5.12(1.13)$ & 0.549 \\
\hline \multicolumn{5}{|c|}{ Growth failure } \\
\hline Absence & 181 (88.3\%) & 97 (93.3\%) & 84 (83.2\%) & \\
\hline Present & 24 (11.7\%) & 7 (6.7\%) & 17 (16.8\%) & 0.042 \\
\hline \multicolumn{5}{|l|}{$\mathrm{TB}(\mu \mathrm{mol} / \mathrm{L})$} \\
\hline Mean (SD) & $160(67.0)$ & 147 (60.6) & $174(70.7)$ & 0.004 \\
\hline \multicolumn{5}{|l|}{$\mathrm{DB}(\mu \mathrm{mol} / \mathrm{L})$} \\
\hline Mean (SD) & $136(60.5)$ & $128(60.3)$ & $144(59.9)$ & 0.058 \\
\hline \multicolumn{5}{|l|}{$\mathrm{IB}(\mu \mathrm{mol} / \mathrm{L})$} \\
\hline Mean (SD) & $24.1(16.1)$ & $21.5(14.4)$ & 26.7 (17.3) & 0.019 \\
\hline \multicolumn{5}{|l|}{$\operatorname{ALT}(\mathrm{IU} / \mathrm{L})$} \\
\hline Mean (SD) & $191(168)$ & 195 (172) & 188 (164) & 0.77 \\
\hline \multicolumn{5}{|l|}{ AST(IU/L) } \\
\hline Mean (SD) & 328 (411) & 344 (514) & 311 (268) & 0.566 \\
\hline \multicolumn{5}{|l|}{ ALP(IU/L) } \\
\hline Mean (SD) & 465 (239) & 452 (236) & 477 (243) & 0.455 \\
\hline \multicolumn{5}{|l|}{ GGT(IU/L) } \\
\hline Mean (SD) & 606 (483) & 646 (514) & 565 (447) & 0.23 \\
\hline \multicolumn{5}{|l|}{ ALB(g/L) } \\
\hline Mean (SD) & 39.1 (5.39) & $39.9(4.94)$ & $38.2(5.70)$ & 0.019 \\
\hline \multicolumn{5}{|l|}{ LDH(IU/L) } \\
\hline Mean (SD) & 348 (113) & 341 (121) & $354(104)$ & 0.416 \\
\hline \multicolumn{5}{|l|}{ INR } \\
\hline Mean (SD) & $1.22(0.486)$ & $1.10(0.259)$ & $1.35(0.618)$ & 0.001 \\
\hline \multicolumn{5}{|l|}{$\mathrm{FIB}(\mathrm{g} / \mathrm{L})$} \\
\hline Mean (SD) & $2.18(0.737)$ & $2.23(0.759)$ & $2.12(0.715)$ & 0.317 \\
\hline \multicolumn{5}{|c|}{ WBC(10^9/L) } \\
\hline Mean (SD) & $12.6(4.77)$ & 12.5 (4.32) & $12.8(5.21)$ & 0.674 \\
\hline \multicolumn{5}{|c|}{ Neutrophil(10^9/L) } \\
\hline Mean (SD) & $4.62(2.93)$ & $4.28(2.16)$ & 4.96 (3.53) & 0.096 \\
\hline \multicolumn{5}{|c|}{ Lymphocyte(10^9/L) } \\
\hline Mean (SD) & 6.54 (3.55) & 6.28 (3.33) & $6.80(3.75)$ & 0.291 \\
\hline \multicolumn{5}{|c|}{ Monocyte(10^9/L) } \\
\hline Mean (SD) & $0.778(0.376)$ & $0.774(0.366)$ & $0.782(0.388)$ & 0.88 \\
\hline \multicolumn{5}{|l|}{ PLT(10^9/L) } \\
\hline Mean (SD) & $413(171)$ & 417 (174) & 409 (168) & 0.758 \\
\hline \multicolumn{5}{|c|}{ Creatinine(umol/L) } \\
\hline Mean (SD) & $20.9(8.86)$ & $21.1(10.7)$ & $20.7(6.41)$ & 0.743 \\
\hline \multicolumn{5}{|l|}{ PELD } \\
\hline Mean (SD) & $8.98(6.06)$ & $6.51(4.66)$ & $11.5(6.30)$ & 0.001 \\
\hline LECT2 & & & & \\
\hline High & 109 (53.2\%) & 29 (27.9\%) & 80 (79.2\%) & \\
\hline Low & 96 (46.8\%) & 75 (72.1\%) & 21 (20.8\%) & 0.001 \\
\hline
\end{tabular}

TB:Total Bilirubin; DB:Direct Bilirubin; IB:Indirect Bilirubin; ALT:Alanine Transaminase; AST:Aspartate Aminotransferase; ALP:Alkaline phosphatase; GGT: $\gamma$-Glutamyltransferase; ALB: Albumin; LDH:Lactate dehydrogenase; INR:International normalized ratio; FIB:Fibrinogen; WBC:White blood cell count; PLT:Platelet; PELD:Pediatric End-stage Liver Disease.

TABLE 2 | Comparison of LECT2 protein expression between biliary atresia liver tissue and control tissue.

\begin{tabular}{|c|c|c|c|c|c|c|}
\hline \multirow[t]{2}{*}{ Groups } & \multirow[t]{2}{*}{ Total } & \multicolumn{2}{|c|}{ LECT2 high expression } & \multicolumn{2}{|c|}{ LECT2 low expression } & \multirow[t]{2}{*}{$p$ Value } \\
\hline & & $\mathbf{n}$ & $\%$ & $\mathbf{n}$ & $\%$ & \\
\hline Biliary atresia & 205 & 180 & 87.8 & 25 & 12.2 & \\
\hline Normal liver & 40 & 3 & 7.5 & 37 & 92.5 & $<0.01$ \\
\hline
\end{tabular}




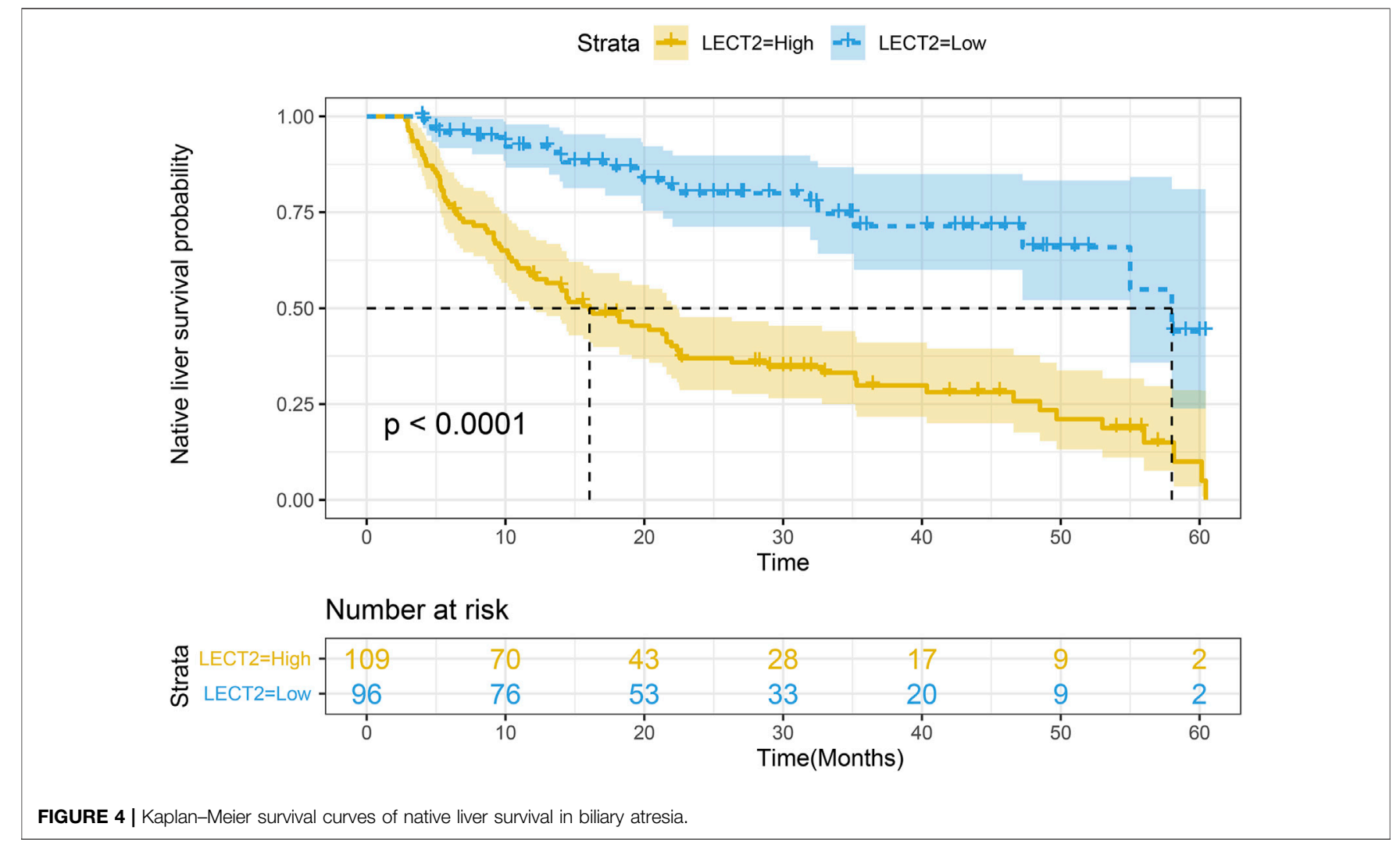

TABLE 3 | Cox regression analysis of native liver survival.

\begin{tabular}{|c|c|c|c|c|c|c|c|c|c|c|c|c|c|c|}
\hline \multirow{3}{*}{$\begin{array}{l}\text { Parameters } \\
\text { Weight(kg) }\end{array}$} & \multicolumn{7}{|c|}{ Univariable analysis } & \multicolumn{7}{|c|}{ Multivariable analysis } \\
\hline & \multicolumn{5}{|c|}{ Hazard ratio $(95 \% \mathrm{Cl})$} & & \multirow{2}{*}{$\begin{array}{c}\boldsymbol{p} \text { Value } \\
0.552\end{array}$} & \multicolumn{6}{|c|}{ Hazard ratio $(95 \% \mathrm{Cl})$} & \multirow[t]{2}{*}{$p$ Value } \\
\hline & 1.089 & ( & 0.823 & - & 1.44 & ) & & & & & & & & \\
\hline $\mathrm{TB}(\mu \mathrm{mol} / \mathrm{L})$ & 1.003 & ( & 1.001 & - & 1.006 & ) & 0.008 & 0.999 & ( & 0.992 & - & 1.007 & ) & 0.845 \\
\hline $\mathrm{DB}(\mu \mathrm{mol} / \mathrm{L})$ & 1 & ( & 1 & - & 1.006 & ) & 0.044 & 0.998 & ( & 0.992 & - & 1.004 & ) & 0.469 \\
\hline $\mathrm{IB}(\mu \mathrm{mol} / \mathrm{L})$ & 1.012 & ( & 1.001 & - & 1.023 & ) & 0.036 & 1.001 & ( & 0.983 & - & 1.018 & ) & 0.954 \\
\hline GGT(IU/L) & 1 & ( & 1 & - & 1.001 & ) & 0.347 & & & & & & & \\
\hline $\operatorname{ALB}(g / L)$ & 1.006 & ( & 0.962 & - & 1.052 & ) & 0.798 & & & & & & & \\
\hline LDH(IU/L) & 1.001 & ( & 0.999 & - & 1.003 & ) & 0.237 & & & & & & & \\
\hline INR & 1.482 & ( & 1.141 & - & 1.925 & ) & 0.003 & 0.357 & ( & 0.085 & - & 1.504 & ) & 0.16 \\
\hline $\mathrm{FIB}(\mathrm{g} / \mathrm{L})$ & 1.078 & ( & 0.771 & - & 1.508 & ) & 0.661 & & & & & & & \\
\hline WBC(10^9/L) & 0.974 & ( & 0.922 & - & 1.03 & ) & 0.357 & & & & & & & \\
\hline Creatinine $(\mu \mathrm{mol} / \mathrm{L})$ & 1.005 & ( & 0.978 & - & 1.034 & ) & 0.714 & & & & & & & \\
\hline PELD & 1.188 & ( & 1.006 & - & 1.418 & ) & 0.045 & 1.019 & ( & 0.985 & - & 1.054 & ) & 0.276 \\
\hline LECT2 & 3.462 & ( & 1.713 & - & 6.993 & ) & 0.001 & 3.702 & ( & 2.085 & - & 6.575 & ) & 0.001 \\
\hline
\end{tabular}

TB:Total Bilirubin; DB:Direct Bilirubin; IB:Indirect Bilirubin; ALT:Alanine Transaminase; AST:Aspartate Aminotransferase; ALP:Alkaline phosphatase; GGT: $\gamma$-Glutamyltransferase; ALB: Albumin; LDH:Lactate dehydrogenase; INR:IIternational normalized ratio; FIB:Fibrinogen; WBC:White blood cell count; PLT:Platelet; PELD:Pediatric End-stage Liver Disease.

levels increased when liver function returned to normal (Sato et al., 2004b). The results of GSEA analysis showed that LECT2 is involved in BA development mainly through regulation of bile acid metabolism, activation of genes involved in the inflammatory response, activation of TNF-a signaling pathway and IL16 signaling pathway. Continued study of these molecular events 
A

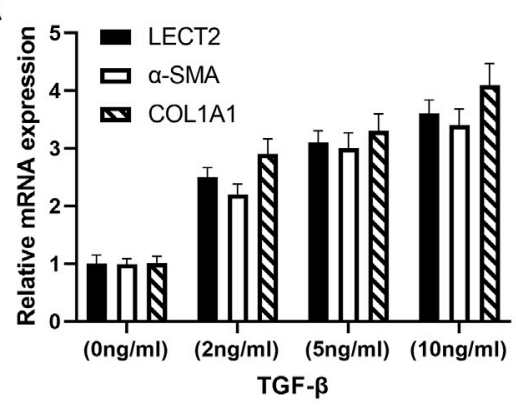

C

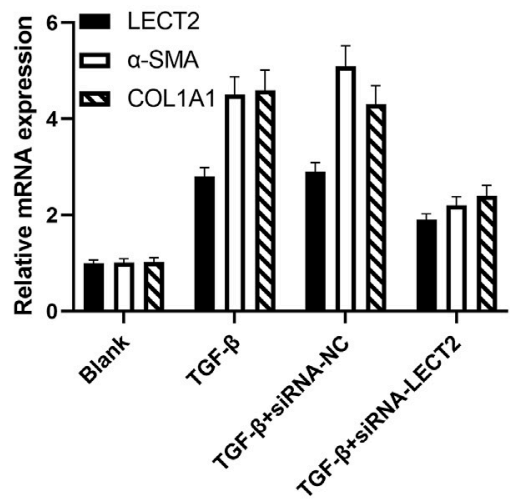

E

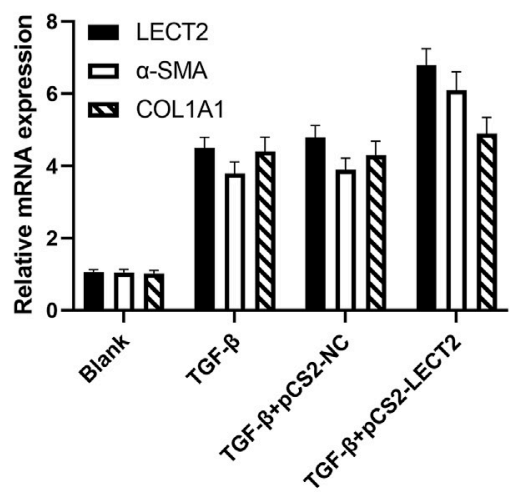

B

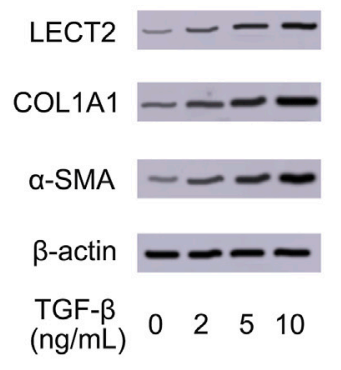

D

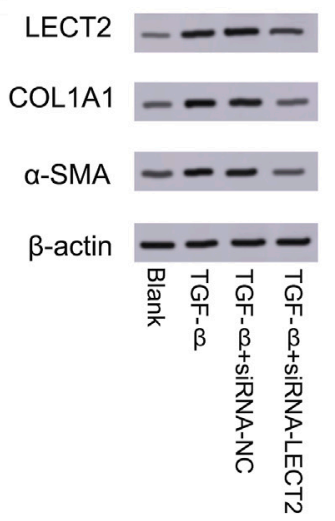

$\mathbf{F}$

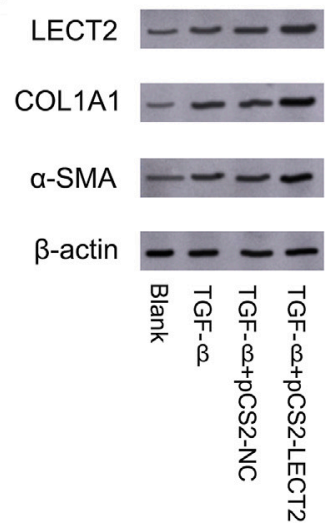

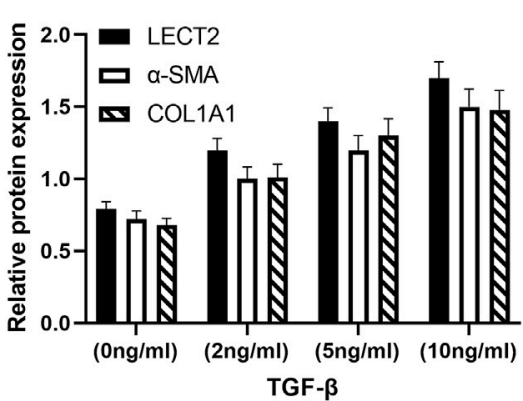

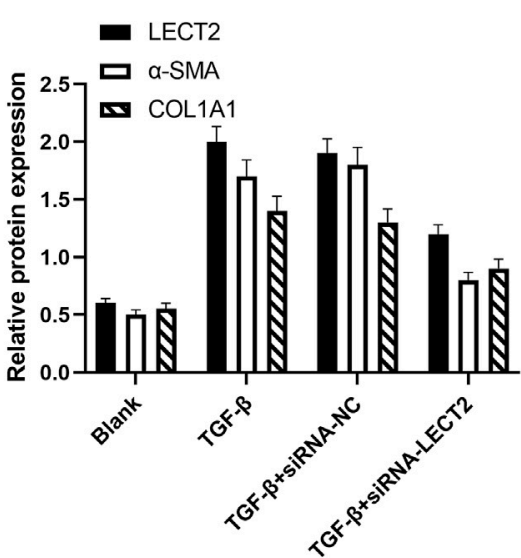

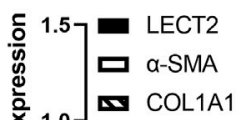

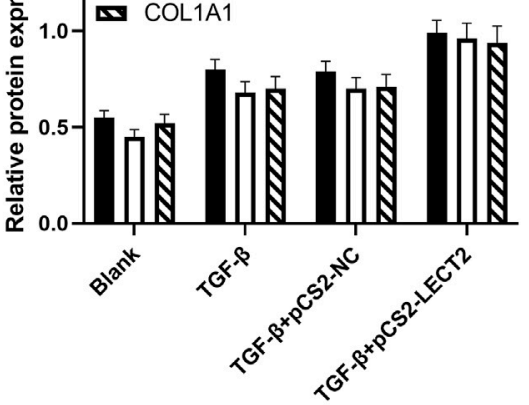

FIGURE 5 | The expression of LECT2, a-SMA and COL1A1 in LX-2 cells (A) The effect of TGF- $\beta$ on LECT2, a-SMA and COL1A1 mRNA (B) The effect of TGF- $\beta$ on LECT2, a-SMA and COL1A1 protein (C) siRNA-LECT2 inhibits the mRNA expression of a-SMA and COL1A1 in LX-2 cells (D) siRNA-LECT2 inhibits the protein expression of a-SMA and COL1A1 in LX-2 cells (E) Overexpression of LECT2 resulted in an increase in a-SMA and COL1A1 mRNA levels (F) Overexpression of LECT2 resulted in an increase in a-SMA and COL1A1 protein levels.

will contribute to a better understanding of the pathogenesis of BA and potentially translate these findings into the clinical arena. In the future, we will expand the collection of clinical samples and conduct further mechanistic studies at the cellular level and animal level using molecular biological experiments to validate the conclusions drawn from this study.

Our immunohistochemistry result also showed that the proportion of LECT2 high expression in BA children was significantly higher than that of control group, suggesting that
LECT2 was highly expressed in BA children and may be involved in the pathogenesis of BA. Previous study showed that LECT2 expression is significantly elevated in nonalcoholic fatty liver disease, and LECT2 induces the development and progression of Nonalcoholic fatty liver disease through the STAT-1 signal pathway (Wang et al., 2021). In lipopolysaccharide or D-galactosamine induced acute liver injury animal model, LECT2 was found to be strongly associated with the prognosis of inflammatory liver disease (Okumura et al., 2017). Regarding the 5 years survival rate 


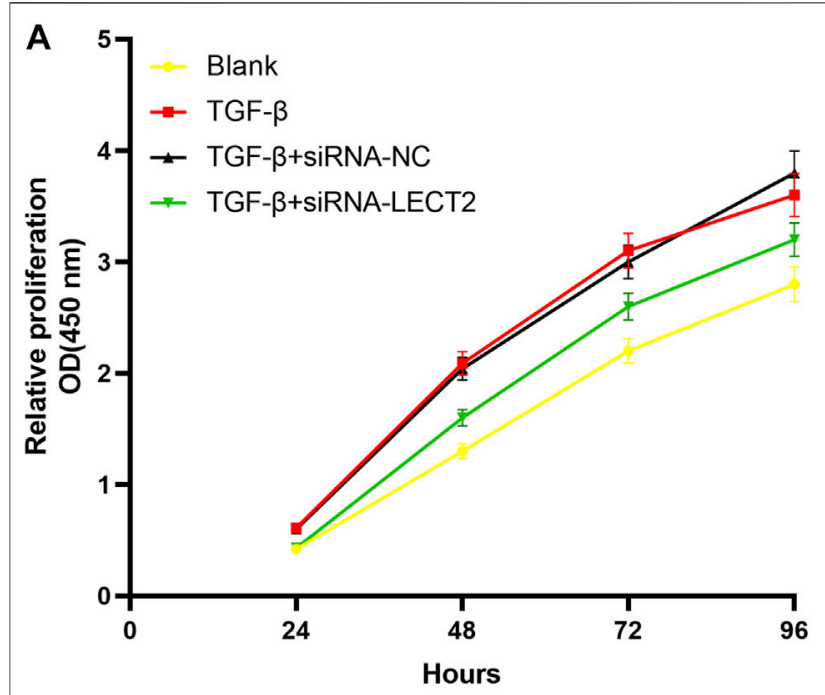

B
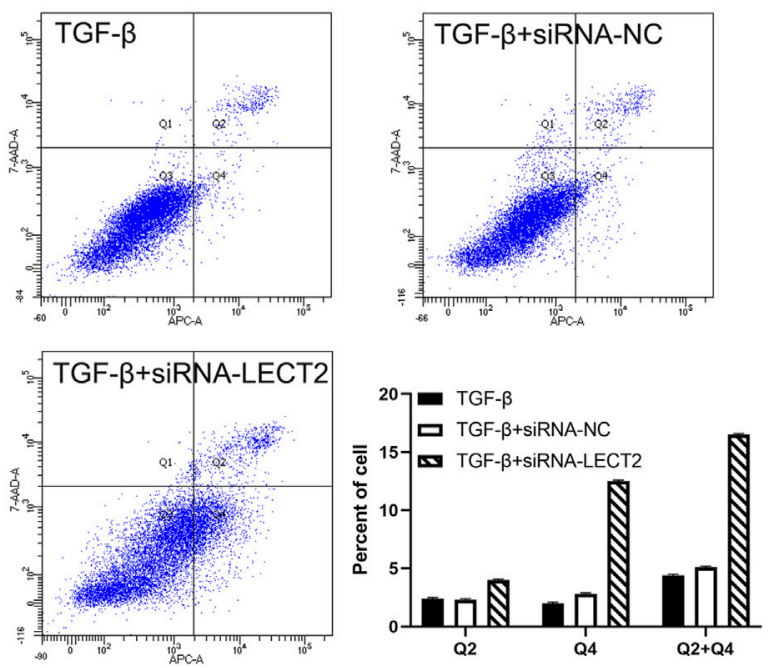

FIGURE 6 | The effect of LECT2 on LX2 cells proliferation and apoptosis (A) Knockdown of LECT2 inhibits the proliferation in activated LX-2 cells (B) Knockdown of LECT2 increase apoptosis in activated LX-2 cells.

without liver transplantation, the 5 years native liver survival rate in Japan is $59.7 \%$ (Nio et al., 2003). The 5 years native liver survival rate in England and Wales is $46 \%$ (Davenport et al., 2011). The 5 years native liver survival rate after Kasai operation in France is $40 \%$ (Chardot et al., 2013). Our finding is consistent with these previous articles. The 5 years native liver survival rate in our hospital is $54.6 \%$, and how to improve the long-term survival of native liver is still the direction we are working on. Several reports have shown that LECT2 may be a biomarker of survival prognosis for patients in various liver disease states. Prior studies that have noted the importance of LECT2 in adult living related donor liver transplantation, serum LECT2 levels decreased immediately after surgery in donors and recipients, suggesting LECT2 is involved in liver regeneration after hepatectomy (Sato et al., 2004a). Previous studies evaluating serum LECT2 observed consistent results on whether LECT2 can be used to predict prognosis of acute liver failure, lower serum LECT2 is associated with better prognosis in adult acute liver failure patients (Slowik et al., 2019). This result is important because LECT2 is a target gene of the $\mathrm{Wnt} / \beta$-catenin pathway and plays a key role in stimulating liver regeneration (Ovejero et al., 2004). LECT2 is also a chemokine for neutrophils and macrophages, which are activated and recruited to the liver during the hepatic recovery phase, and lower serum LECT2 levels may indicate less tissue necrosis and a more rapid remission of the inflammatory response (Antoniades et al., 2012). However, the intrahepatic role of LECT2 may be different than the systemic role of LECT2, and the role of LECT2 in liver tissue may be different from that in serum, which requires further investigation. Our study showed that the native liver survival rate of low LECT2 expression group and high LECT2 expression group were 78.1 and $26.6 \%$ respectively, suggesting LECT2 protein expression is associated with the prognosis of BA children after Kasai surgery. A multivariate COX regression analysis indicate that the high LECT2 expression was an independent prognostic factor affecting native liver survival, suggest that LECT2 can be used as an auxiliary indicator to determine the prognosis of BA.

Progressive liver fibrosis is one of the most important factors affecting the prognosis of biliary atresia children, and hepatic stellate cells are the key cells involved in the development of biliary atresia liver fibrosis (Song et al., 2021). TGF- $\beta$ is considered to be an important pro-fibrotic cytokine. We induced LX-2 cell activation with different concentrations of TGF- $\beta(2,5$, and $10 \mathrm{ng} / \mathrm{ml})$. Our results showed that the expression of LECT2, $a$-SMA, and COL1A1 was significantly increased in LX-2 cells. The results suggested that the pro-fibrotic effect of LECT2 may be related to its promotion of hepatic stellate cells activation. CCK8 results showed that transfection with siRNA-LECT2 significantly inhibited LX-2 proliferation, and flow cytometry results showed that siRNALECT2 transfection significantly promoted LX-2 cell apoptosis. These results suggest that LECT2 may regulate liver fibrosis by regulating HSC cell proliferation and apoptosis.

There were some limitations in our study. First, this was a single-center retrospective study, but all patients were operated by the same surgical team with standard surgical steps could increase the consistency. Second, the molecular mechanism of LECT2 in the prognosis of BA is unclear, further studies are needed to elucidate the multiple functions of LECT2 in BA.

In conclusion, LECT2 is highly expressed in the BA liver tissues, and the upregulation of LECT2 expression indicates a poor prognosis. The high LECT2 expression was an independent prognostic factor affecting native liver survival. The LECT2 protein might be used as an auxiliary indicator to determine the prognosis of BA children. Detection of LECT2 in liver tissues in BA children may help to select the appropriate time for liver transplantation and evaluate the clinical prognosis.

\section{DATA AVAILABILITY STATEMENT}

The datasets presented in this study can be found in online repositories. The names of the repository/repositories 
and accession number(s) can be found below: https://www. ncbi.nlm.nih.gov/, GSE15235: https:/www.ncbi.nlm.nih.gov/, GSE46960. Other data and materials used during the current study are available from the corresponding author on reasonable request.

\section{ETHICS STATEMENT}

The studies involving human participants were reviewed and approved by the West China Hospital, Sichuan University. Written informed consent to participate in this study was

\section{REFERENCES}

Antoniades, C. G., Quaglia, A., Taams, L. S., Mitry, R. R., Hussain, M., Abeles, R., et al. (2012). Source and Characterization of Hepatic Macrophages in Acetaminophen-Induced Acute Liver Failure in Humans. Hepatology 56, 735-746. doi:10.1002/hep.25657

Bijl, E. J., Bharwani, K. D., Houwen, R. H., and de Man, R. A. (2013). The LongTerm Outcome of the Kasai Operation in Patients with Biliary Atresia: a Systematic Review. Neth. J. Med. 71, 170-173. doi:10.1007/s11845-013-0958-2

Chang, C. H., Bryce, C. L., Shneider, B. L., Yabes, J. G., Ren, Y., Zenarosa, G. L., et al. (2018). Accuracy of the Pediatric End-Stage Liver Disease Score in Estimating Pretransplant Mortality Among Pediatric Liver Transplant Candidates. JAMA Pediatr. 172, 1721070-1721077. doi:10.1001/ jamapediatrics.2018.2541

Chardot, C., Carton, M., Spire-Bendelac, N., Le Pommelet, C., Golmard, J.-L., and Auvert, B. (1999). Prognosis of Biliary Atresia in the Era of Liver Transplantation: French National Study from 1986 to 1996. Hepatology 30, 606-611. doi:10.1002/hep.510300330

Chardot, C., Buet, C., Serinet, M.-O., Golmard, J.-L., Lachaux, A., Roquelaure, B., et al. (2013). Improving Outcomes of Biliary Atresia: French National Series 1986-2009. J. Hepatol. 58, 1209-1217. doi:10.1016/j.jhep.2013.01.040

Cielecka-Kuszyk, J., Janowska, M., Markiewicz, M., Czubkowski, P., OstojaChyżyńska, A., Bierła, J., et al. (2021). The Usefulness of Immunohistochemical Staining of Bile Tracts in Biliary Atresia. Clin. Exp. Hepatol. 7, 41-46. doi:10.5114/ceh.2021.104676

Davenport, M., Ong, E., Sharif, K., Alizai, N., McClean, P., Hadzic, N., et al. (2011). Biliary Atresia in England and Wales: Results of Centralization and New Benchmark. J. Pediatr. Surg. 46, 1689-1694. doi:10.1016/ j.jpedsurg.2011.04.013

Hartley, J. L., Davenport, M., and Kelly, D. A. (2009). Biliary Atresia. Lancet 374, 3741704-3741713. doi:10.1016/S0140-6736(09)60946-6

He, L., Ip, D. K. M., Tam, G., Lui, V. C. H., Tam, P. K. H., and Chung, P. H. Y. (2021). Biomarkers for the Diagnosis and post-Kasai Portoenterostomy Prognosis of Biliary Atresia: a Systematic Review and Meta-Analysis. Sci. Rep. 3 (11), 11692. doi:10.1038/s41598-021-91072-y

Killcoyne, S., Carter, G. W., Smith, J., and Boyle, J. (2009). Cytoscape: a Community-Based Framework for Network Modeling. Methods Mol. Biol. 563, 219-239. doi:10.1007/978-1-60761-175-2_12

Langfelder, P., and Horvath, S. (2008). WGCNA: an R Package for Weighted Correlation Network Analysis. BMC Bioinformatics 9, 9559. doi:10.1186/14712105-9-559

Luo, Y., Coskun, V., Liang, A., Yu, J., Cheng, L., Ge, W., et al. (2015). Single-cell Transcriptome Analyses Reveal Signals to Activate Dormant Neural Stem Cells. Cell 161, 1611175-1611186. doi:10.1016/j.cell.2015.04.001

Nio, M., Ohi, R., Miyano, T., Saeki, M., Shiraki, K., Tanaka, K., et al. (2003). Fiveand 10-year Survival Rates after Surgery for Biliary Atresia: a Report from the Japanese Biliary Atresia Registry. J. Pediatr. Surg. 38, 997-1000. doi:10.1016/ s0022-3468(03)00178-7

Okumura, A., Suzuki, T., Dohmae, N., Okabe, T., Hashimoto, Y., Nakazato, K., et al. (2009). Identification and Assignment of Three Disulfide Bonds in Mammalian Leukocyte Cell-Derived Chemotaxin 2 by Matrix-Assisted Laser provided by the participants' legal guardian/next of kin. Written informed consent was obtained from the individual(s), and minor(s)' legal guardian/next of kin, for the publication of any potentially identifiable images or data included in this article.

\section{AUTHOR CONTRIBUTIONS}

BX: study concept, management and coordination responsibility for the research activity planning.MK: study concept, experiment design, data analysis and writing the manuscript.

Desorption/ionization Time-Of-Flight Mass Spectrometry. Biosci. Trends 3, 139-143.

Okumura, A., Saito, T., Tobiume, M., Hashimoto, Y., Sato, Y., Umeyama, T., et al. (2017). Alleviation of Lipopolysaccharide/D -Galactosamine-Induced Liver Injury in Leukocyte Cell-Derived Chemotaxin 2 Deficient Mice. Biochem. Biophys. Rep. 12, 166-171. doi:10.1016/j.bbrep.2017.09.011

Ovejero, C., Cavard, C., Périanin, A., Hakvoort, T., Vermeulen, J., Godard, C., et al. (2004). Identification of the Leukocyte Cell-Derived Chemotaxin 2 as a Direct Target Gene of $\beta$-catenin in the Liver. Hepatology 40, 167-176. doi:10.1002/ hep. 20286

Saito, T., Okumura, A., Watanabe, H., Asano, M., Ishida-Okawara, A., Sakagami, J., et al. (2004). Increase in Hepatic NKT Cells in Leukocyte Cell-Derived Chemotaxin 2-deficient Mice Contributes to Severe Concanavalin A-Induced Hepatitis. J. Immunol. 1173, 579-585. doi:10.4049/ jimmunol.173.1.579

Sásik, R., Calvo, E., and Corbeil, J. (2002). Statistical Analysis of High-Density Oligonucleotide Arrays: a Multiplicative Noise Model. Bioinformatics 18, 1633-1640. doi:10.1093/bioinformatics/18.12.1633

Sato, Y., Watanabe, H., Kameyama, H., Kobayashi, T., Yamamoto, S., Takeishi, T., et al. (2004a). Changes in Serum LECT 2 Levels during the Early Period of Liver Regeneration after Adult Living Related Donor Liver Transplantation. Transplant. Proc. 36, 2357-2358. doi:10.1016/j.transproceed.2004.07.006

Sato, Y., Watanabe, H., Kameyama, H., Kobayashi, T., Yamamoto, S., Takeishi, T., et al. (2004b). Serum LECT2 Level as a Prognostic Indicator in Acute Liver Failure. Transplant. Proc. 36, 2359-2361. doi:10.1016/ j.transproceed.2004.07.007

Slowik, V., Borude, P., Borude, P., Jaeschke, H., Woolbright, B. L., Lee, W. M., et al. (2019). Leukocyte Cell Derived Chemotaxin-2 (Lect2) as a Predictor of Survival in Adult Acute Liver Failure. Transl. Gastroenterol. Hepatol. 4, 17. doi:10.21037/ $\operatorname{tgh} .2019 .03 .03$

Song, W., Sun, L.-Y., and Zhu, Z.-J. (2021). Effects of Previous Kasai Surgery on Gut Microbiota and Bile Acid in Biliary Atresia with End-Stage Liver Disease. Front. Med. 8, 704328. doi:10.3389/fmed.2021.704328

Subramanian, A., Tamayo, P., Mootha, V. K., Mukherjee, S., Ebert, B. L., Gillette, M. A., et al. (2005). Gene Set Enrichment Analysis: a Knowledge-Based Approach for Interpreting Genome-wide Expression Profiles. Proc. Natl. Acad. Sci. 102, 15545-15550. doi:10.1073/pnas.0506580102

Tanisawa, K., Taniguchi, H., Sun, X., Ito, T., Kawakami, R., Sakamoto, S., et al. (2017). Visceral Fat Area Is a strong Predictor of Leukocyte Cell-Derived Chemotaxin 2, a Potential Biomarker of Dyslipidemia. PLoS One 12, e0173310. doi:10.1371/journal.pone.0173310

Wang, J., Chen, Y., Pan, R., Wu, C., Chen, S., Li, L., et al. (2021). Leukocyte Cellderived Chemotaxin 2 Promotes the Development of Nonalcoholic Fatty Liver Disease through STAT-1 Pathway in Mice. Liver Int. 41, 777-787. doi:10.1111/ liv.14816

Xu, M., Xu, H.-H., Lin, Y., Sun, X., Wang, L.-J., Fang, Z.-P., et al. (2019). LECT2, a Ligand for Tie1, Plays a Crucial Role in Liver Fibrogenesis. Cell 178, 1478-1492. doi:10.1016/j.cell.2019.07.021

Zheng, H., Miyakawa, T., Sawano, Y., Yamagoe, S., and Tanokura, M. (2013). Crystallization and Preliminary X-ray Analysis of Human Leukocyte CellDerived Chemotaxin 2 (LECT2). Acta Cryst. Sect. F 69, 316-319. doi:10.1107/ s1744309113003758 
Zhou, K., Xie, G., Wen, J., Wang, J., Pan, W., Zhou, Y., et al. (2016). Histamine Is Correlated with Liver Fibrosis in Biliary Atresia. Dig. Liver Dis. 48, 921-926. doi:10.1016/j.dld.2016.05.001

Conflict of Interest: The authors declare that the research was conducted in the absence of any commercial or financial relationships that could be construed as a potential conflict of interest.

Publisher's Note: All claims expressed in this article are solely those of the authors and do not necessarily represent those of their affiliated organizations, or those of the publisher, the editors and the reviewers. Any product that may be evaluated in this article, or claim that may be made by its manufacturer, is not guaranteed or endorsed by the publisher.

Copyright (c) 2021 Kong and Xiang. This is an open-access article distributed under the terms of the Creative Commons Attribution License (CC BY). The use, distribution or reproduction in other forums is permitted, provided the original author(s) and the copyright owner(s) are credited and that the original publication in this journal is cited, in accordance with accepted academic practice. No use, distribution or reproduction is permitted which does not comply with these terms. 